\title{
THE CULTURES OF GRIEF: THE PRACTICE OF POST-MORTEM PHOTOGRAPHY AND ICONIC INTERNALIZED VOICES
}

\author{
LUCA TATEO
}

\begin{abstract}
I develop an exploratory analysis of "post-mortem photography", a social practice existing in different cultures. The study, part of a larger project in Denmark, "The culture of grief", combines Dialogical Self Theory, mainly concerning verbal and textual objects, with the iconic framework of affective semiosis to discuss the function of taking and keeping pictures of dead persons as if they were still alive or just sleeping. How can this practice and artifact culturally mediate the experience of death and the elaboration of grief? What kind of inner dialogue is developed through the internalization of this specific kind of presence/ absence? These are some of the preliminary questions I will try to answer by discussing some examples of post-mortem photography from the 19th and 20th centuries in different countries.
\end{abstract}

Key words: affective semiosis; polyphony; iconic internalization; grief culture

The metaphor in Dialogical Self Theory (DST) of internalized voices in the society of self has led to the development of research which concentrates on verbal and textual objects. Yet verbal communication is only a part of human meaning-making. Another important aspect is represented by images. Very few works have discussed the iconic aspects of DST (Ruck \& Slunecko, 2008). Our life space is filled with meaningful others, who are sometimes present to us in a form other than language or voice. Every home, wallet, office, or even car is filled with images of people with whom we have an affective relationship. Sometimes the image substitutes the person herself, as in the case of someone who is no longer part of our daily life, because of death, distance, a break up or because they are simply unreachable, like popstars or divinities. The iconic side of the other in the self is nicely expressed in the Picture of Dorian Gray (Wilde, 2006). I will just briefly present a key moment in the book, when Dorian Gray first sees the just finished portrait of him by the painter Basil Hallward:

When he saw it he drew back, and his cheeks flushed for a moment with pleasure. A look of joy came into his eyes, as if he had recognised himself for the first time. He stood there motionless and in wonder, dimly conscious that Hallward was speaking to him, but not catching the meaning of his words. The sense of his own beauty came on him like a revelation. He had never felt it before. (Wilde, 2006, p. 24) 
In this short scene, three positions are explicitly mentioned: Dorian Gray himself, the painter Basil Hallward and the portrait. For the sake of precision, there is a fourth character, Lord Henry Wotton-Gray's old college friend and protector-who is watching the whole scene and who commissioned and supervised the painting. Yet in this short analysis, Lord Henry is only relevant to the extent that we can imagine that part of Dorian's reaction is to include the lord as an audience.

Dorian Gray walks around the canvas after Hallward paints the last stroke and catches sight of his portrait for the first time. Wilde describes his bodily reactions ("he drew back" and "flushed" with "pleasure"). The second moment is Dorian recognising the portrait as his own image ("he had recognised himself for the first time"). The third moment, as I interpret this excerpt, is the moment the portrait is internalized as a central part of the self ("The sense of his own beauty came on him like a revelation") and a new I-position is formed ("He had never felt it before"). Meanwhile, two other voices can be heard: the painter, who is the author of the portrait and who speaks to Dorian both through his voice ("Hallward was speaking to him") and his artifact; and Lord Henry, who is the commissioner of the work and Dorian's "partner". In the society of the self, the movement seems to be away from the existing position of "I-as-Henry-protégée" to "I-as-handsome-man"). It seems that Dorian Gray is a nice example of the role images play in the dialogical dynamic of self. However, the mastery of Wilde's art is that he never actually shows the painting. The reader can construct her own idea of this magical and evil portrait without the visual clues. From the perspective of Dorian Gray, the process has to do with the actual image, which can be included in the everyday life space, though be hidden. From the perspective of the reader, this image is never accessible as such, only through verbal narrative. Ruck and Slunecko (2008) take this a step further using a visible portrait of Frida Kahlo that enables them to show the dialogical construction of the meaning of the double portrait.

There are other cases in real life, where we deal with other kind of real images, and my attempt here will be to explore, theoretically, whether it is possible to study the use of images in the dialogic dynamic of self. To this end, I will develop an exploratory analysis of a specific social practice that exists in different cultures - so called "post-mortem photography". It is part of a larger project in Denmark, "The culture of grief", and adopts the framework of affective semiosis (Tateo, 2018a) to explore how taking pictures of the corpses of loved ones, and keeping the pictures in everyday life, can produce an internalization not only of voices, but also of images of significant others. What happens when the society of the self is populated not only by voices but also by images? What is the function of taking and keeping pictures of corpses as if they were still alive or just sleeping? How can this practice and artifact culturally mediate the experience of death and to elaborate grief? What kind of inner dialogue is developed through the internalization of this specific kind of presence/ absence? These are some of the preliminary questions I will try to answer by discussing some examples of post-mortem photography from the $19^{\text {th }}$ and $20^{\text {th }}$ centuries in different countries.

\section{Grief and affective logic}

There is growing interest in phenomena related to the emotion of grief and ways of coping with this life event (Bandini, 2015; Brinkmann, 2017). It has been prompted by the World 
Health Organization recognising the diagnosis of "Prolonged grief disorder" in 2018. In secular societies, grief seems to have become a medicalized issue rather than a very common existential experience. The main arguments seem to be that post-modern societies have removed death and dying — as well as suffering and ageing — from everyday life, turning them into problematic individual issues that should be treated as "illnesses" (Golden, Dalgleish \& Mackintosh, 2007; Kaplan, 2016). As Blauner aptly put it 15 years ago:

In modern societies, the bereaved person suffers from a paucity of ritualistic conventions in the mourning period. He experiences grief less frequently, but more intensely, since his emotional involvements are not diffused over an entire community, but are usually concentrated on one or a few people. Since mourning and a sense of loss are not widely shared, as in premodern communities, the individualization and deritualization of bereavement make for serious problems in adjustment. There are many who never fully recover and "get back to normal," in contrast to the frequently observed capacity of the bereaved in primitive societies to smile, laugh, and go about their ordinary pursuits the moment the official mourning period is ended. The lack of conventionalized stages in the mourning process results in an ambiguity as to when the bereaved person has grieved enough and thus can legitimately and guiltlessly feel free for new attachments and interests. Thus at the same time that death becomes less disruptive to the society, its prospects and consequences become more serious for the bereaved individual. (Blauner, 1992, pp. 26-27)

The elaboration of the experience of grief, through the process of bereavement, exhibits all the features of a specific form of affective relation to the world that I have called "affective logic" (Ciompi, 1997; Tateo, 2018a). Each cultural context provides some social suggestions (rituals, practices, dress-codes etc.) for eliciting some of the affects and conducts that the person is expected to experience, and inhibit others (Cacciatore \& DeFrain, 2015). Individual experiences of loss are personal trajectories that unfold within the framework provided by such social suggestions; nevertheless, they are unique trajectories. The negotiation of these is full of ambivalences, resistance and turns; rather than being a linear process of grief. Selectively internalizing aspects of the social suggestions about how bereavement "ought" to be experienced is a way of actively establishing a relationship with the cultural context. In turn, expressing a selective form of conduct (e.g. dressing in black, mourning, being on one's own) affects the personal experience of grief.

I assume that grief follows a socially guided "affective logic" which can manage the inherent contradictions of loss through the mediation of internalized cultural artifacts, such as photographs of the missed person. For instance, in terms of affective logic, the two statements "I am grieving THEREFORE I am wearing black" and "I am wearing black THEREFORE I am grieving" are equally valid. Affective logic is based on imaginative processes, and the loss acquires value in relation to the person's continuous striving for "what's next". We hypothesize that imaginative elaboration plays a fundamental role in the co-construction of past and future in relation to grief.

Imaginative play with past unrealized possibilities ("What is $\mathrm{X}$ will not be $\mathrm{X}$ but could have been X") and future uncertainty ("What is not X but will be X") can play an important part in the complex and prolonged experience of grief. Social suggestions help individuals to co-construct their personal trajectories, by encouraging the inhibiting of particular window of possibilities (what can be, what ought to be, what is not allowed, etc.) (Tateo, 2018b). For 
instance, medical discourse (treatments, life expectancy, etc.) or religious beliefs (afterlife, etc.) can play a role in promoting or inhibiting a range of potential imaginative trajectories in children or young people on how a parent's chronic or terminal illness may play out. With the increasingly multicultural nature of contemporary society, there is a multiplication and diversification of social suggestions that may enlarge the windows of opportunity but also weaken the social suggestions specific to a given community, introducing a further element of complexity in the negotiation between the individual and context in the trajectory of personal grief. Den Elzen (2017) has recently used the construct of Dialogical Self theory (Hermans \& Gieser, 2011) to explore the grief experience in the memoirs of young widows. She reports what seems to be a common feature of the grief experience (Brinkmann, 2017; Den Elzen, 2017; Golden, Dalgleish, \& Mackintosh, 2007; Neimeyer, 2007): a feeling of the "fragmentation of selfhood" (Den Elzen, 2017, p. 57), which needs to be somehow accounted for and reconstructed dialogically. This aspect directly points to the idea of grieving as an experience related to the loss of "the other in me". In different cultural practices one can observe the use of photography in different phases of the grief process. So, it is possible this medium acts as a mediation tool in grieving and in the internalization of the "other in me". Ruck and Slunecko (2008) suggest "the interpretation of family- or other photographs in order to reconstruct the relations between internal and external I-positions." (p. 285) In the next section, I will try to develop an initial hypothesis about the iconic dimension related to the specific phenomenon of grief in the society of the self.

\section{Images, death and significant others}

Why do people take pictures of dead people? Why do they keep an image of the dead person in their life space? The practice of depicting a person we have lost and want to remember is found widely across many epochs and cultures (Aytemiz, 2013; Borgo, Licata \&

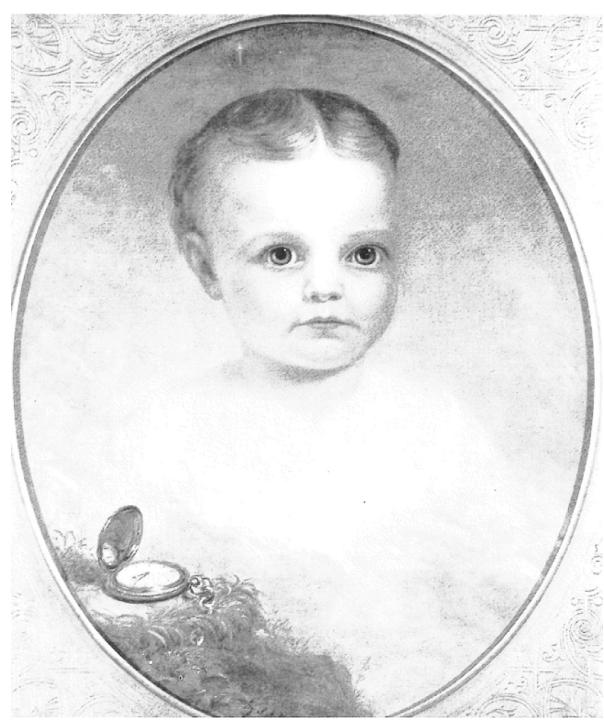
Iorio, 2016; Hafsteinsson, 1999; Mendelyté, 2012; Michelson, Blehart, Hochberg, James \& Frader, 2013; Ruby, 1984; 1989; Stuart \& Rawski, 2001). Before the introduction of photography, this practice was mediated by other artifacts, such as painted portraits (Figure 1).

Figure 1. Shephard Alonzo Mouft (18071868) New York, 'A Portrait of Camille 1868'. Oil on canvas. (Courtesy of The Museum of Stony Brook, New York. Bequest of Dorothy DeBevoise Mount, 1959.) (in Ruby, 1984, p. 203). 


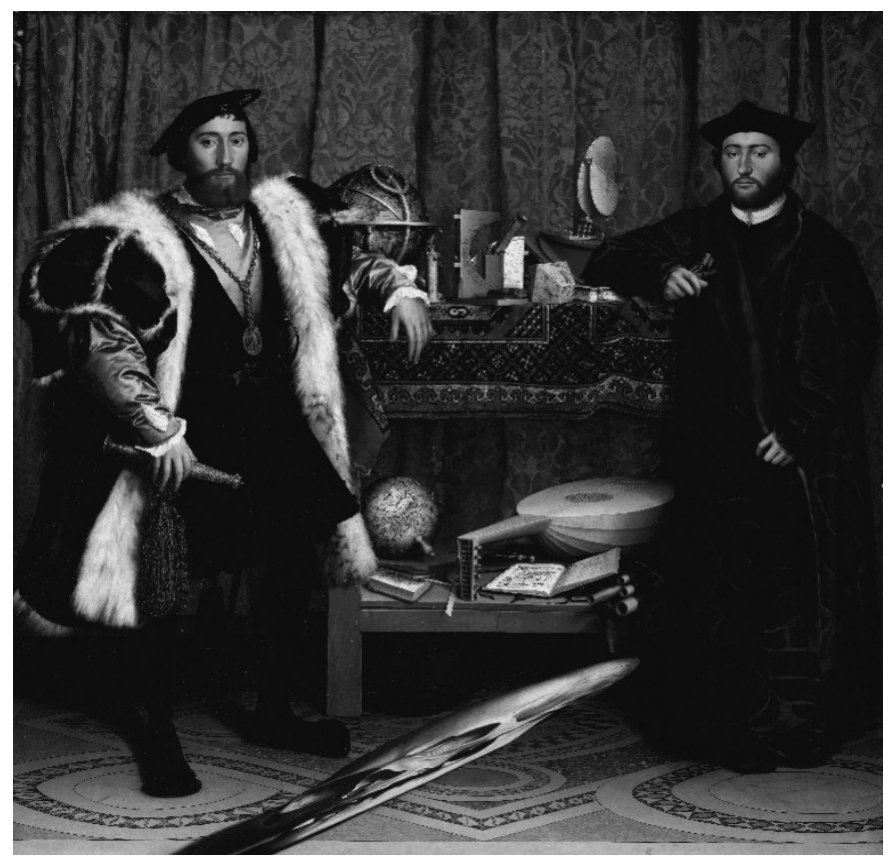

Figure 2. The Ambassadors, by Hans Holbein (1533), National Gallery, London - This file is from:Holbein-ambassadors.jpg, Public Domain, https://commons.wikimedia.org/w/index. php?curid $=64818856$

This very old pictorial genre was related to two different "branches": on the one hand there was the tradition of the portrait of an affluent person (Figure 2).

Holbein's famous painting The Ambassadors probably portrays Jean de Dinteville, who in 1533 was the 29-year-old ambassador of France, and his friend Georges de Selve, the 25-yearold Bishop of Lavaur who visited London in the same year. The double portrait is filled with symbols of power and wisdom; the objects on the shelf represent the characteristics of the two nobles and of the country they represent as well as the forthcoming turmoil in England, just before Henry the VIII broke away from the Catholic Church (North, 2004). But there is a strange detail in the lower central part of the painting that immediately stands out. It is an apparent mistake; a deformed image that does not fit the painting's overall perspective. If one looks carefully, the features become familiar, and we realize the deformation is due to the angle of observation. Indeed, if the observer adopts a specific position, standing to the far right of the painting, then the anamorphic image of a skull becomes visible. It is a classic example of a memento mori (Latin for "remember [that you have] to die"):

a religious theory and practice of reflection on mortality, considering the vanity and the transient nature of all earthly life and pursuits (Hallam \& Hockey, 2001). It developed as a widespread art theme, especially during the 16th and 17th centuries, through sometimes very complex systems of iconography. (Tateo, 2016, p. 47) 
Painting was of course a very expensive way of producing portraits, so it was reserved to the wealthy classes (Ruby, 1984). This kind of portrait was meant to establish an internal dialectic between wealth and vanity, the ephemeral and eternal, life and death. A memento mori was a way of mediating the internalization of the appropriate I-position ("I-as-fated-todie") with the intention of regulating moral conduct. Once the person portrayed has passed away, the meaning of the memento changes, to the extent that the message is addressed to the living offspring. After death, the skull signifies the person is no longer alive.

On the other hand, the second type of portrait (Figure 1) is commissioned and executed post-mortem. It was initially reserved to very prominent or rich people, but with the rise of the affluent middle class after the industrial revolution, the commissioners of these portraits increased in number. It was also an easy way for young artists to enter the circles of the bourgeoisie and meet the future commissioners of more valued kinds of works. In these postmortem portraits, like the one in Figure 1, the appearance of the subject in their lifetime was retained, and the portrait was often hung in the living room of the house.

The paintings are only now being recognised for what they are, because the subject is so often portrayed as if alive, with disguised death symbols in the background, for example, a willow tree or a wilted flower in the subject's hand, or in the case of 'The Portrait of Camille' by Shephard Alonzo Mount, a clock with its hands stopped. (Ruby, 1984, p. 204)

It is in this context that the Dorian Gray portrait takes on a dialogical meaning. Is it a portrait of an extraordinary, handsome man of his age or is it a metaphorical post-mortem portrait in which the subject is frozen in time? Is Dorian "frowning" on first glancing at his portrait out of pride or augury? It is probably both, in the art of Oscar Wilde. The cultural mediation of grief has also been exerted through the pervasive presence of cultural artifacts such as portraits, hanging in the "periphery" of sight in houses and public places, but always available to become central when required (Tateo, 2018a). Portraying life and death together, was a way of walking between them, both giving them a presence and making them part of the potential future trajectories of any wealthy Western person (Borgo, Licata \& Iorio, 2016). At the same time, the subject of the portrait remains somehow available as an image to be internalized by those closest, in the only way the technology of the time allowed.

A big change occurred when photography became available to the larger public in the second half of the $19^{\text {th }}$ century (Ruby, 1984). Post-mortem portraiture, a tool of cultural mediation, rapidly became more accessible to the lower social classes: grief became more democratic. Post-mortem portrait photography spread from Victorian England to the United States and other Western countries. Borgo, Licata and Iorio (2016) identify different genres of this portraiture. The most common is "the last sleep" and has its roots in the Christian Protestant idea of the time that death was only a temporary sleep while waiting for the resurrection (Ruby, 1994). This implies the idea of preserving the integrity of the corpse, for instance through the use of embalming and make up, and portraying the deceased as if asleep. This was very common for instance in the case of babies (Figure 3).

Another style, "is defined by the deceased's eyes staring into the lens" (Borgo, Licata \& Iorio, 2016, p. 106) and is called "Alive but Dead" (Figure 4).

This style was so important that the first photographers/painters used it to add open eyes to the original plate by drawing them in afterwards. 


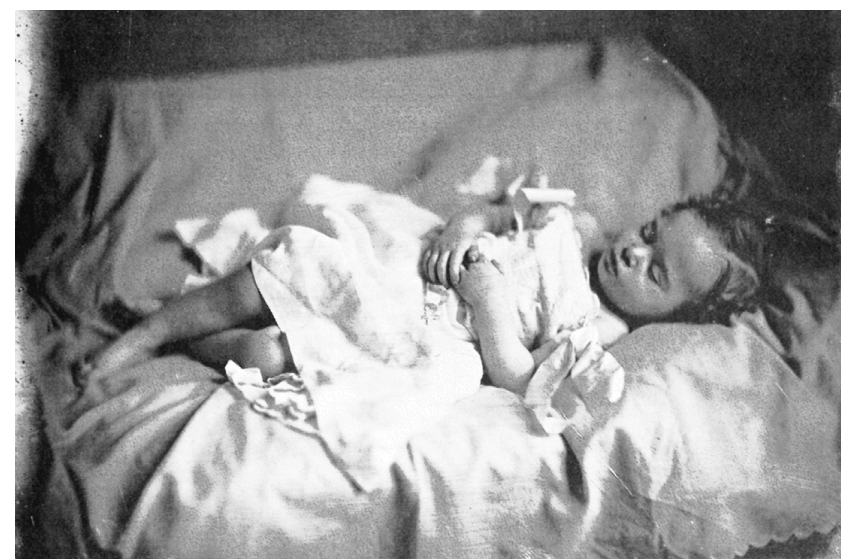

Figure 3. Southworth and Hawes, Boston. Portrait of anonymous child, ca. 1850. Full-plate daguerreotype. (Courtesy George Eastman House, Rochester, IMP No. 74:193:130.) (in Ruby, 1984, p. 204)

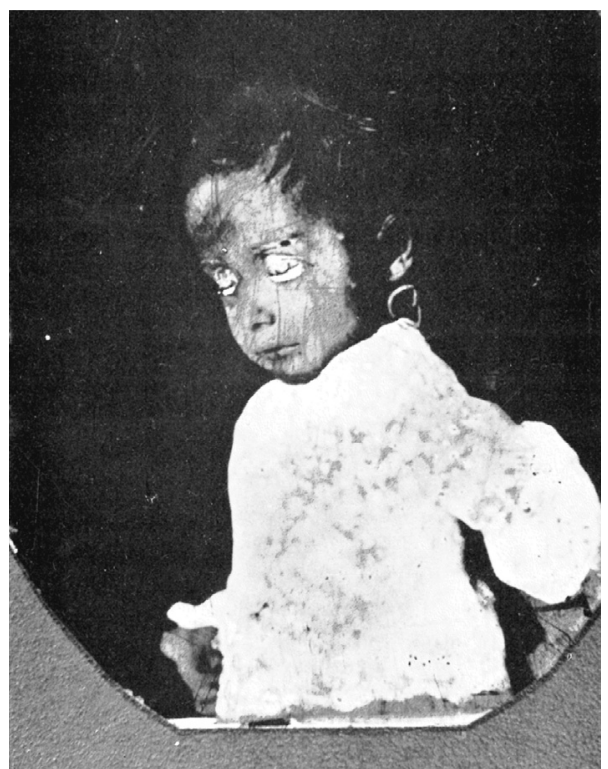

Figure 4. Photographer unknown. Portrait of anonymous deceased child, ca. 1890. Full-plate tintype with painted eyes. (Collection of Ruby, 1984, p. 207)

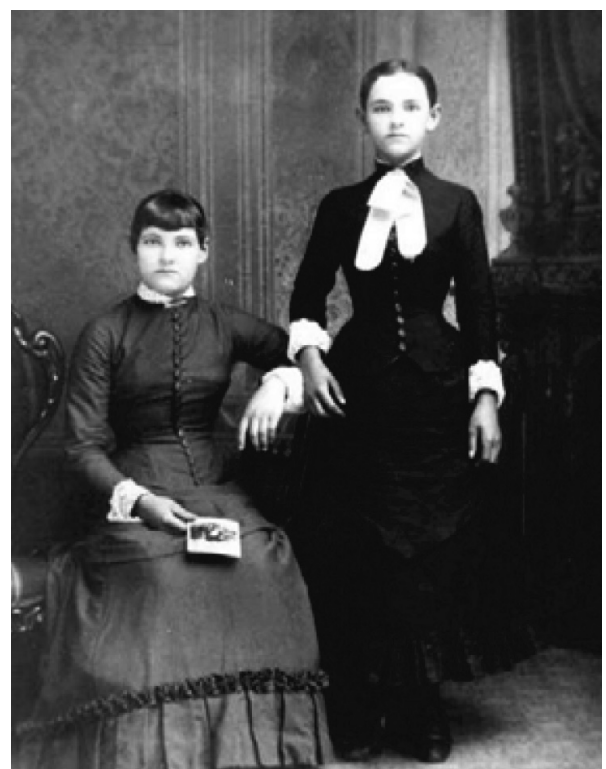

Figure 5. "An exemplification of the third style of post-mortem photography: who is the dead girl?" (Borgo, Licata \& Iorio, 2016, p. 113) 
In the third style, "the deceased person is hidden within the family, and usually it is quite difficult to recognize the deceased from the living. Furthermore, the typical funeral iconographs were not used. Only a meticulous observation can capture details to identify the deceased, such as: an expressionless look or the central position of the dead. The deceased was inserted perfectly as "alive among the living"' (Borgo, Licata \& Iorio, 2016, p. 106) (Figure 5).

This type of post-mortem portrait, common in England during the Victorian Age (Mendelyté, 2012), is also the most commonly discussed in the popular media. Indeed, of all the styles, it looks the most morbid and disquieting. Photographers became specialized in the use of techniques to create scenes in such a way that the corpse was arranged and photographed at the right moment, when post-mortem changes (e.g. rigor mortis) would allow the best complexion and posture. For example, the corpse would have been hung on a kind of support for the head and the back.

If one considers this specific genre of post-mortem photography from the Dialogical Self perspectiveDialogical Self, it is more understandable and less morbid nowadays. As Blauner (1992) explains:

Death creates a further problem because of the contradiction between society's need to push the dead away and its need 'to keep the dead alive'. The social distance between the living and the dead must be increased after death, so that the group first, and the most affected grievers later, can reestablish their normal activity without a paralyzing attachment to the corpse. Yet the deceased cannot simply be buried as a dead body: The prospect of total exclusion from the social world would be too anxiety-laden for the living, aware of their own eventual fate. The need to keep the dead alive directs societies to construct rituals that celebrate and ensure a transition to a new social status, that of spirit, a being now believed to participate in a different realm. (Blauner, 1992, p. 26)

Yet death also creates a problem with the "other in me": a highly ambivalent experience in which I as a person "need to push the dead away and its need 'to keep the dead alive'." (Blauner, 1992, p. 26) as the internalized I-position in the society of the self, especially if is a close and beloved person. There is great social pressure today to the resolution of grief in a way that is suited to the post-modern way of life, to returning to productivity and well-being as soon as possible (Brinkmann, 2017). At the same time, human collectives, especially late-modern Western societies, generally push death and suffering into the background (Keohane, Petersen \& Van den Bergh, 2017), as an unwanted disturbance of the fluidity of existence or the fear we no longer have the resources to cope. This relates to our close suffering, while the diffused, daily and distant suffering of unspecified others does not apparently disturb us much, though it is continuously broadcasted. We do not grieve for "others", for we no longer have a means of mediation that would enable this emotion to be internalized. Again, something happened with the emergence of photography, which incidentally is contemporary to the rise of modern mass war technologies. Another type of post-mortem photography was the portrayal of mass death during wars (Figure 6) or in natural disasters. The first large-scale use of this kind of photography started with the American Civil War (1861-1865). It became common in almost all the conflicts from the second half of the $19^{\text {th }}$ century onward. 


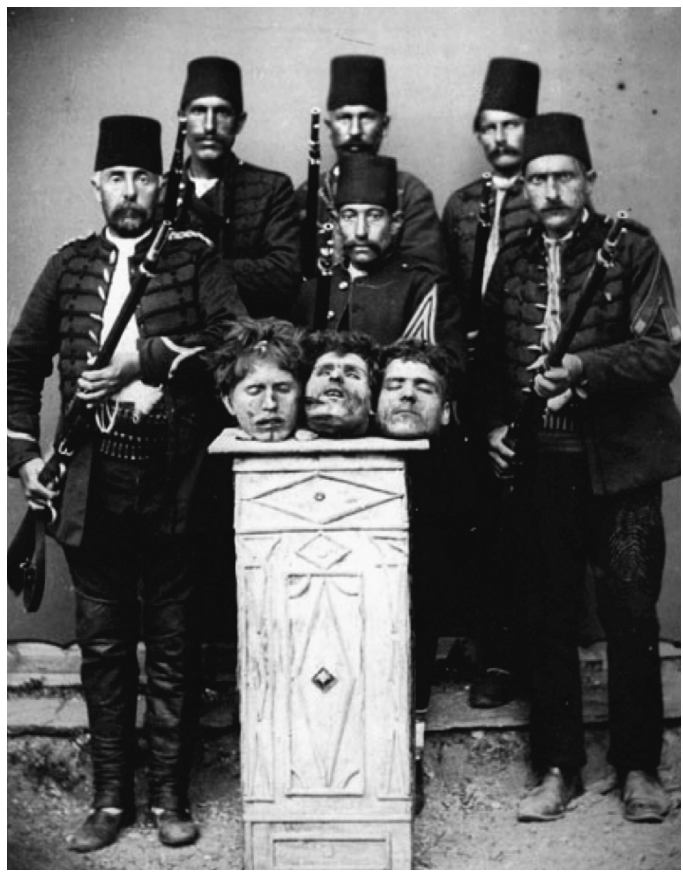

Figure 6. Ottoman-era studio photographs with heads of rebels from Macedonia or the Balkan states in the early 1900s (Eldem, 2005, p. 189, reproduced in Aytemiz, 2013, p. 330).

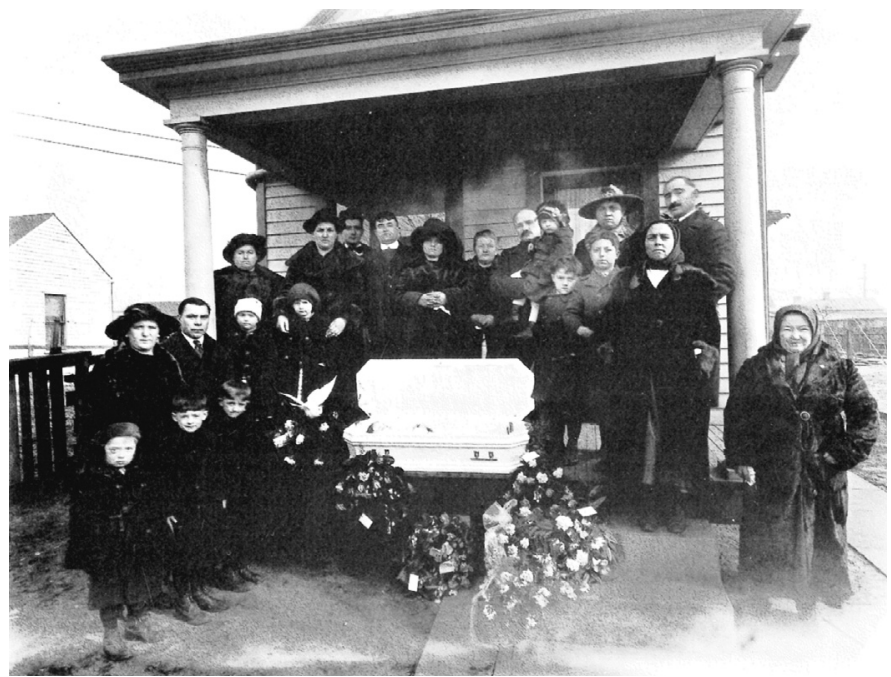

Figure 7. Caufield and Shook. Funeral group. ca. 1930, 8 x 10 inch photograph. (Courtesy of the University of Louisville Photographic Archive.) (in Ruby, 1984, p. 218) 
Why do people photograph victims of war or disasters? Figure 6 is a barbaric and violent practice of the past. Yet, we can still easily find such images in the media today, and they do not strike us as "abnormal". Iraq, Afghanistan, Syria, New Orleans, Haiti, Ruanda are all sources of an incredible amount of post-mortem photography, that seems to mediate no internalization process. It would be hard to find an emerging new I-position as "I-asempathizing-with-a-Syrian-war-victim". They would remain on the periphery of the self, and I would not experience complicated grief.

Not surprisingly, the progressive dismissal of death and dying from everyday life has been accompanied by a parallel change in post-mortem photography (Ruby, 1984). Indeed, the focus of the image has moved from the person's portrait to the funeral narrative (Figure 7).

The portrait includes the deceased but the context of the ritual dominates as subject of remembering. The suggestion is that that what is important is the collective gathering, the collective remembering and mourning. We can see the living people more than the deceased. The narrative of grief involves a collective dimension, which is also a belonging: a new position "I-as-part-of-a-mourning-community".

\section{Conclusion: Is it possible to study the iconic Dialogical Self?}

In this initial theoretical reflection, I have tried to discuss two main questions. The first is whether we can understand Dialogical Self, the emerging of self positions and their relations, and the process of internalization and externalization not only in terms of voices but also in terms of images. The second question is whether we can consider this process as a way to understand some of the process of the cultural mediation of grief. For this purpose I have discussed examples of different forms of iconic representation in art and photography at different moments in human history. I have suggested that studying post-mortem portraiture could be an entry point to understanding the relationship between dialogicality, iconicity

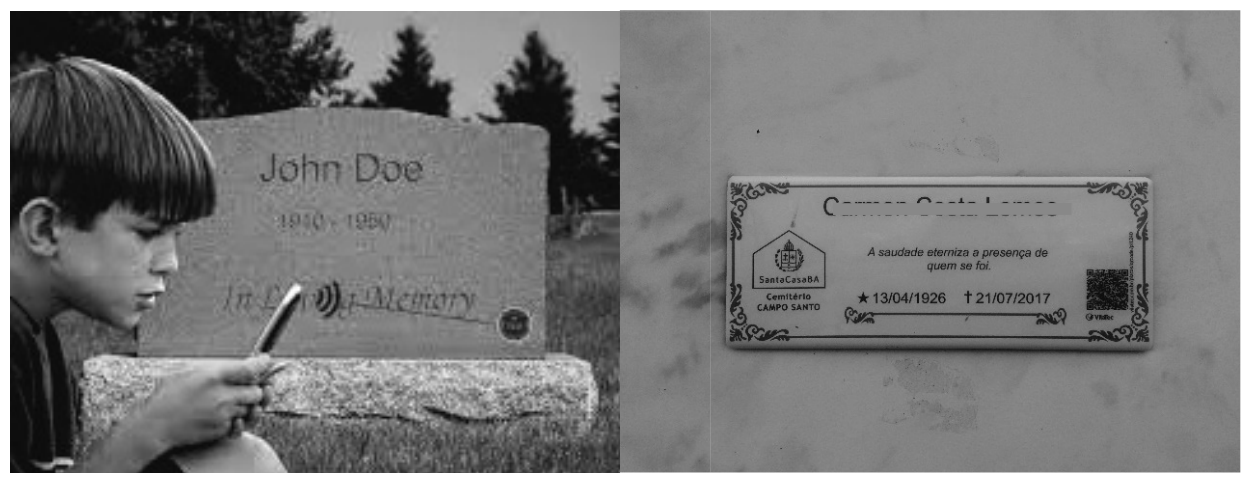

Figure 8. Qr-codes on headstones for watching multimedia content about the deceased (thanks to my student Anna Emilie Sander Christensen for finding this in a cemetery in May 2018) 
and the cultural mediation of grief. There are a number of clinical experiences where we are trying to use post-mortem photography as a tool for the elaboration of grief, for instance in cases of potentially complicated grief as in perinatal loss (Michelson, Blehart, Hochberg, James, \& Frader, 2013).

This work is of course purely theoretical, so far. The idea has many limitations, like for instance the impossibility of studying the actual psychological experiences of people living in the era of early post-mortem photography. Another important limitation is the absence of a good methodology for studying the construction of iconic side of I-positions and the role of cultural mediation. The approach of affective logic (Tateo, 2018a) may be suitable as the theoretical basis for such work. The relevance of the image in grief is, however, still worth investigating (Figure 8).

New phenomena are emerging that seem to endorse the hypothesis that images play a mediational role in grief, following affective logic. One recent trend is the "living headstone" (Figure 8): the use of QR-codes on the tombstone and tablets to exactly give "life", "voice" and "body" to the deceased, continuing the tradition of "alive but dead" images.

\section{References}

Aytemiz, P. (2013). Death photography in Turkey in the late 1800s and early 1900s: Defining an area of study. Early Popular Visual Culture, 11(4), 322-341. doi:10.1080/17460654.2013.831738

Bandini, J. (2015). The medicalization of bereavement: (Ab)normal Grief in the DSM-5. Death Studies, 39(6), 347-352. doi: 10.1080/07481187.2014.951498

Blauner, R. (1992). Death and social structure. Illness, Crisis \& Loss, 2(2), 22-32.

Borgo, M., Licata, M., \& Iorio, S. (2016). Post-mortem photography: The edge where life meets death? Human and Social Studies, 5(2), 103-115. doi: 10.1515/hssr -2016-00016

Brinkmann, S. (2017). Could grief be a mental disorder? Nordic Psychology, published online: 25 Sep 2017. doi: 10.1080/19012276.2017.1381038

Cacciatore, J., \& DeFrain, J. (Eds.). (2015). The world of bereavement: Cultural perspectives on death in families. Cham: Springer.

Ciompi, L. (1997). The concept of affect logic: An integrative psycho-socio-biological approach to understanding and treatment of schizophrenia. Psychiatry, 60(2), 158-170.

Den Elzen, K. (2017). Exploring the nature of the Dialogical Self: The young widow memoir. European Journal of Life Writing, 6, 40-61.

Eldem, E. (2005). Istanbul'da Ölüm: Osmanl1-Islam Kültüründe Ölüm ve Ritüelleri. Istanbul: Osmanlı Bankası Arşiv ve Araştırma Merkezi Yayınları.

Golden, A. M., Dalgleish, T., \& Mackintosh, B. (2007). Levels of specificity of autobiographical memories and of biographical memories of the deceased in bereaved individuals with and without complicated grief. Journal of Abnormal Psychology, 116(4), 786.

Hafsteinsson, S. B. (1999). Post-mortem and funeral photography in Iceland. History of Photography, 23(1), 49-54. doi: 10.1080/03087298.1999.10443798

Hermans, H. J., \& Gieser, T. (2011). History, main tenets and core concepts of Dialogical Self theory. In H. J. Hermans \& T. Gieser (Eds.), Handbook of Dialogical Self theory (pp. -22). Cambridge: Cambridge University Press.

Kaplan, C. (2016). Personal conceptions of death in young Czech adults. Human Affairs, 26(2), pp. 167-185. doi:10.1515/humaff-2016-0017

Keohane, K., Petersen, A., \& Van den Bergh, B. (2017). Late modern subjectivity and its discontents: Anxiety, depression and Alzheimer's disease. London: Taylor \& Francis. 
Mendelyté, A. (2012). Death (in the eye) of the beholder: An encounter with Victorian post-mortem photography. Synaesthesia: Communication across Cultures, 1(3), 84-90.

Michelson, K. N., Blehart, K., Hochberg, T., James, K., \& Frader, J. (2013). Bereavement photography for children: Program development and health care professionals' response. Death Studies, 37(6), 513-528. doi: 10.1080/07481187.2011.649942

Neimeyer, R. A. (2007). Narrating the Dialogical Self: Toward an expanded toolbox for the counselling psychologist. Counselling Psychology Quarterly, 19(1), 105-120. doi: 10.1080/09515070600655205

North, J. (2004). The Ambassadors' secret: Holbein and the world of the Renaissance. London: Phoenix.

Ruby, J. (1984). Post-Mortem portraiture in America. History of Photography, 8(3), 201-222. doi: 10.1080/03087298.1984.10442223

Ruby, J. (1989). Portraying the dead. OMEGA-Journal of Death and Dying, 19(1), 1-20.

Ruck, N., \& Slunecko, T. (2008). A portrait of a Dialogical Self: Image science and the Dialogical Self. International Journal for Dialogical Science, 3(1), 261-290.

Stuart, J., \& Rawski, E. S. (2001). Worshiping the ancestors: Chinese commemorative portraits. Washington, DC: Smithsonian Institution and Stanford University Press.

Tateo, L. (2016). Fear. In V. Glăveanu, L. Tanggaard, \& C. Wegener (Eds.), Creativity-A new vocabulary (pp. 43-51). London: Palgrave Macmillan.

Tateo, L. (2018a). Affective semiosis and affective logic. New Ideas in Psychology, $48 C$ (2018) pp. $1-11$.

Tateo, L. (2018b). Educational dilemmas. A Cultural Psychological Perspective. London: Routledge.

Wilde, O. (1891/2006). The picture of Dorian Gray. Oxford: Oxford University Press.

Communication \& Psychology

Aalborg University

Aalborg

9220

Denmark

Email: luca@hum.aau.dk 